\title{
DIMENSIONAMENTO DE UMA CÉLULA DE ATERRO SANITÁRIO DE PEQUENO PORTE PARA A CIDADE DE GUAJERU - BA
}

\section{ARTIGO ORIGINAL}

DIAS, Gilson Da Rocha ${ }^{1}$, FIGUEIRA NETO, Moacyr De Souza ${ }^{2}$, MARTINS, Roseli Oliveira Guedes ${ }^{3}$

DIAS, Gilson Da Rocha. FIGUEIRA NETO, Moacyr De Souza. MARTINS, Roseli Oliveira Guedes. Dimensionamento de uma célula de aterro sanitário de pequeno porte para a cidade de Guajeru - BA. Revista Científica Multidisciplinar Núcleo do Conhecimento. Ano 06, Ed. 06, Vol. 08, pp. 113-136. Junho de 2021. ISSN: 24480959, Link de acesso: https://www.nucleodoconhecimento.com.br/engenhariacivil/cidade-de-guajeru, DOI: 10.32749/nucleodoconhecimento.com.br/engenhariacivil/cidade-de-guajeru

\section{RESUMO}

O presente artigo trata do dimensionamento de uma célula para o projeto de um aterro sanitário do município de Guajeru - Ba, observando o perfil da cidade, sua população, suas características geológicas e solo, bem como seu potencial gerador de resíduos sólidos urbanos. A Lei oํ 14.026/2020, estabeleceu que municípios com população de até 50 mil habitantes, terão o prazo limite até 2024 para substituir os atuais lixões e aterros controlados, por aterros sanitários, obedecendo as normas técnicas especificadas, visando o desenvolvimento e avanço do saneamento básico, bem como o aumento dos cuidados com meio ambiente. Neste sentido, o estudo apresenta

\footnotetext{
${ }^{1}$ Graduando Engenharia Civil Pela Faculdade Independente Do Nordeste.

${ }^{2}$ Graduando Engenharia Civil Pela Faculdade Independente Do Nordeste.

${ }^{3}$ Mestre Em Engenharia Civil Pela Universidade Federal De Viçosa E Professora Adjunta Do Colegiado De Engenharia Civil Da Fainor.
}

$\mathrm{RC}: 88511$

Disponível em: https://www.nucleodoconhecimento.com.br/engenharia-civil/cidade-de-guajeru 
as primeiras soluções para a implantação de um aterro na cidade de Guajeru, devendo o município adotar medidas sérias e estratégicas em busca da adequação às exigências do marco regulatório, implantando um ciclo completo de gestão e tratamento dos resíduos sólidos, que vai desde a conscientização da população com a criação de um programa de coleta seletiva e cooperativa de catadores, para incentivar a separação dos materiais recicláveis, até a destinação final dos resíduos em aterro sanitário. Inúmeros autores tratam do tema e apresentam com detalhes as etapas e sistemas que compõem um aterro sanitário, bem como suas funções. Para o desenvolvimento dos cálculos, a pesquisa apresenta como solução três equações para determinar a massa, o volume e a vida útil de uma célula, possibilitando a adequação do projeto a uma área preestabelecida. Deste modo, a célula do aterro sanitário da cidade de Guajeru foi dimensionada para uma população de pouco mais de 10 mil habitantes, com implantação em uma área de aproximadamente $10.000 \mathrm{~m}^{2}$, resultando numa vida útil estimada maior que 16 anos. Em suma, a instalação do aterro sanitário no município proporcionará uma melhora na qualidade de vida dos seus habitantes, com impacto direto nos indicadores da saúde pública, além de reduzir os impactos ambientais causados pelos resíduos sólidos depositados de forma inapropriada.

Palavras-chave: Saneamento básico, resíduos sólidos, aterro sanitário.

\section{INTRODUÇÃO}

O aumento desenfreado da produção de Resíduos Sólidos Urbanos (RSU), chamado comumente de lixo, proveniente do atual crescimento populacional é atualmente um dos maiores problemas ambientais das pequenas, médias e grandes cidades do Brasil.

Em decorrência deste aumento significativo no volume dos RSU, a disposição final deste material ganhou uma atenção especial por parte dos órgãos governamentais competentes, e a partir disso surge um novo sistema de descarte e tratamento,

$\mathrm{RC}: 88511$

Disponível em: https://www.nucleodoconhecimento.com.br/engenharia-civil/cidade-de-guajeru 
chamado de aterro sanitário. Aterro sanitário nada mais é que um local de descarte dos resíduos sólidos oriundos de residências, indústrias, hospitais e construção, sendo que grande parte desse material formado não é reciclável, e a partir dessa técnica, busca minimizar os impactos que o lixo provoca à natureza e a saúde pública (BIDONE, 2001).

No Brasil, a criação da Política Nacional de Resíduos Sólidos a partir da Lei no 12.305/2010 foi um importante marco para o processo de gerenciamento dos resíduos sólidos, consequentemente estabelecendo diversas diretrizes e responsabilidades. A lei estabelece metas ambiciosas e importantes a fim de preservar o meio ambiente e a saúde pública, com o fim dos lixões e dos aterros controlados.

As condições de salubridade ambiental na maioria dos municípios ainda são precárias devido a deficiência ou ausência de serviços públicos de saneamento básico, sendo agravado pela falta de planejamento municipal para o gerenciamento dos resíduos, devido às intervenções fragmentadas ou descontinuadas por parte dos gestores municipais, representando um desperdício de recursos e baixa eficácia na resolução do problema.

De acordo com Política Nacional de Saneamento Básico (PNSB, 2008), atualmente, o Brasil produz uma quantidade alta de resíduos sólidos, em torno de 183.488 toneladas por dia, sendo que a região Nordeste produz cerca de 47.206 toneladas por dia, ficando atrás apenas do Sudeste com 68.181 toneladas por dia. A PNSB informa também que 50,8\% dos municípios ainda utilizam o lixão como destinação final para os resíduos. Por outro lado, há um destaque na área de reciclagem de material que teve um aumento significativo no número de programas de coleta seletiva, passando de 451 unidades no ano 2000 para 994 unidades em 2008. Neste contexto, o incremento no processo de reciclagem é decorrente de um trabalho de conscientização e criação de espaços destinados a esta finalidade, considerando que a destinação correta do lixo e a reciclagem são aspectos fundamentais para a redução no volume dos resíduos que seriam destinados aos aterros. $\mathrm{O}$ acesso a estas

$\mathrm{RC}: 88511$

Disponível em: https://www.nucleodoconhecimento.com.br/engenharia-civil/cidade-de-guajeru 
informações é de fundamental importância na conscientização da sociedade, no que tange da importância do processo de separação dos resíduos e sua destinação correta.

Com base na atual situação das cidades brasileiras referente ao marco regulatório de saneamento básico, pode-se notar que há um déficit em relação ao cumprimento da Política Nacional de Resíduos Sólidos (PNRS) que estabelece diretrizes à gestão e ao gerenciamento dos resíduos sólidos, sendo este um problema crônico da atualidade que ainda está longe de ser resolvido por completo. A lei estabelece metas importantes para a preservação do meio ambiente e da saúde pública, como o fim dos lixões e aterros controlados, mas existe um grande problema no cumprimento dessa lei, e isso atinge principalmente cidades pequenas, devido à falta de recursos e a escassez de profissionais capacitados para a implantação de aterro sanitário. Proveniente das dificuldades abordadas, é de suma importância o aprofundamento em estudos bibliográficos e artigos científicos referente à elaboração de projetos de aterro sanitário de pequeno porte, tais estudos permitem o avanço necessário para que cidades como Guajeru no sudoeste do estado da Bahia, e outras do mesmo porte possam enfrentar esses problemas que afetam o meio ambiente, a sociedade e a economia.

O marco da PNRS estabelece um prazo até o ano de 2024, para cidades com menos de 50 mil habitantes, no qual se espera um reflexo positivo em todos os setores do saneamento, organizando a maneira como as cidades lidam com o lixo e consequentemente trazendo um cenário mais sustentável para todos.

O trabalho apresentado tem como objetivo realizar o dimensionamento de uma célula para um projeto de aterro de disposição final de resíduos sólidos de pequeno porte para a cidade de Guajeru - BA, observando o cumprimento da ABNT NBR 15849:2010 e da ABNT NBR 8419:1992 e para atender a Lei no 14.026/2020 que rege o novo marco de saneamento básico, além de identificar os elementos e sistemas que compõem um aterro sanitário.

$\mathrm{RC}: 88511$

Disponível em: https://www.nucleodoconhecimento.com.br/engenharia-civil/cidade-de-guajeru 
O presente estudo busca realizar o dimensionamento de uma célula para o projeto de aterro sanitário, utilizando as características geológicas do Estado da Bahia para verificar a viabilidade da implantação do aterro mediante análise dos critérios ambientais, além de estimar o volume dos resíduos sólidos gerados pelo município.

\section{FUNDAMENTAÇÃO TEÓRICA}

\subsection{RESÍDUOS SÓLIDOS}

Ao falar em aterro sanitário, há a necessidade de uma melhor compreensão sobre o significado de resíduo sólido, para tanto a conceituação jurídica sobre o tema é apresentada no inciso XVI, do art. 3ํㅡ, da Lei 12.305/2010 que institui a Política Nacional de Resíduos Sólidos. A citada legislação prescreve:

Art. 3․ Para os efeitos desta Lei, entende-se por: [...] XVI - resíduos sólidos: material, substância, objeto ou bem descartado resultante de atividades humanas em sociedade, a cuja destinação final se procede, se propõe proceder ou se está obrigado a proceder, nos estados sólido ou semi-sólidos, bem como gases contidos em recipientes e líquidos cujas particularidades tornem inviável o seu lançamento na rede pública de esgotos ou em corpos d'água, ou exijam para isso soluções técnicas ou economicamente inviáveis em face da melhor tecnologia disponível. (BRASIL, 2010).

É imprescindível que haja soluções técnicas ou economicamente viáveis para uma disposição final adequada dos resíduos sólidos gerados pelas atividades humanas, tendo em vista que os resíduos gerados apresentam grande complexidade e diversidade, onde as características biológicas, químicas e físicas são de acordo com suas atividades geradoras (GONÇALVES, 2004).

\subsection{ATERRO CONTROLADO}

O aterro controlado, segundo a ABNT NBR 8849:1985 é um método utilizado para a disposição de resíduos sólidos urbanos no solo, esse método causa diversos danos à saúde pública, ao meio ambiente e a economia, este modelo de aterro é realizado

RC: 88511

Disponível em: https://www.nucleodoconhecimento.com.br/engenharia-civil/cidade-de-guajeru 
utilizando o cobrimento com uma camada de terra na conclusão de cada jornada de trabalho.

Tal procedimento não utiliza técnicas como a impermeabilização do solo, a drenagem do chorume e do lixiviado, ou até mesmo a queima adequada dos gases gerados, originando uma poluição localizada comprometendo a qualidade do solo e das águas subterrâneas como mostra a Figura 1.

Figura 1 - Modelo de um aterro controlado.

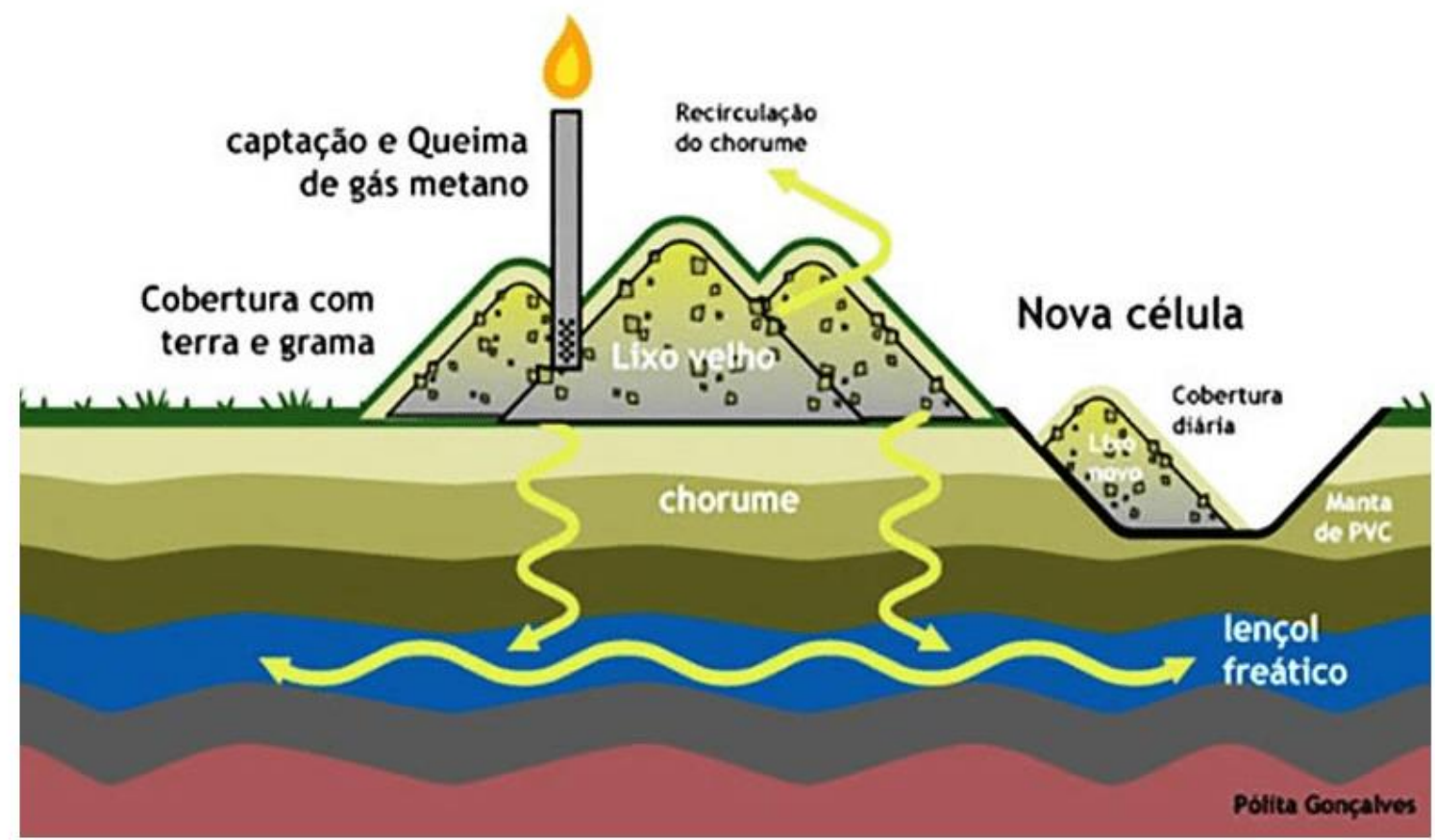

Fonte: $\quad<h t t p s: / / w w w . h y p e v e r d e . c o m . b r / d i f e r e n c a s-e n t r e-l i x a o-a t e r r o-c o n t r o l a d o-e-$ aterro-sanitario/>, acesso em fevereiro de 2021.

Observa-se na Figura 1 a percolação do chorume, provocando a contaminação do lençol freático, o que não ocorre num sistema de aterro sanitário.

RC: 88511

Disponível em: https://www.nucleodoconhecimento.com.br/engenharia-civil/cidade-de-guajeru 


\title{
2.3 ATERRO SANITÁRIO
}

O aterro sanitário é um local de destinação correta para os resíduos sólidos gerados desenfreadamente pelas atividades humanas, tais como: resíduos hospitalares, de áreas comerciais, residencial, das indústrias e da construção civil, sendo que boa parte desses materiais são recicláveis (BIDONE, 2001).

\begin{abstract}
O aterro sanitário é uma das alternativas de tratamento para esses resíduos sólidos, os aterros possuem um solo impermeabilizado para que não haja a contaminação das áreas do entorno e também acontece a monitoria das emissões de gases, são utilizados métodos para armazenar os dejetos na menor área possível para se obter um menor volume, sendo assim cobertos frequentemente com camadas de terra (FERREIRA, 2011, p.13).
\end{abstract}

Para a implantação de um aterro sanitário é necessário técnicas apropriadas para o manejo com os resíduos sólidos e de como estes serão dispostos no solo, atendendo a critérios específicos, evitando assim diversos danos para a saúde pública e para o meio ambiente (MAZZER; CAVALCANTI, 2004).

Conforme a ABNT NBR 8419:1992, um aterro sanitário deve realizar um ciclo completo de tratamento dos resíduos sólidos, considerando os líquidos e gases provenientes da decomposição dos mesmos. Para tanto, um aterro deve dispor de sistemas de tratamento do chorume e lixiviado, coleta e tratamento dos gases, além de sistema de impermeabilização e drenagem eficiente.

\subsubsection{SISTEMA DE IMPERMEABILIZAÇÃO DA CÉLULA}

O aterro sanitário é um local onde se destina diversos tipos de resíduos, e para que seja um sistema que não polua o meio ambiente, o solo deve passar por um processo de compactação e impermeabilização a fim de evitar vazamentos de material líquido proveniente da decomposição dos resíduos para o solo, ocasionando a contaminação do lençol freático. Segundo CEMPRE (2010), o sistema de impermeabilização do solo deve apresentar características em que haja durabilidade, compatibilidade química, física e biológica com os resíduos que serão depositados, e estanqueidade.

RC: 88511

Disponível em: https://www.nucleodoconhecimento.com.br/engenharia-civil/cidade-de-guajeru 
Os solos utilizados para a compactação devem ser de material argiloso, que além da compactação e dependendo das dimensões do aterro sanitário, também pode-se utilizar um geossintético, mais especificamente uma geomembrana de polietileno de alta densidade (PEAD). A aplicação de geossintético em sistemas de impermeabilização do solo é de larga utilização em alguns países, como o Estados Unidos, Alemanha e Brasil (CEMPRE, 2010).

Visando a importância da proteção do meio ambiente, o processo de impermeabilização do fundo do aterro sanitário deve seguir um rigoroso controle tecnológico. A Figura 2 representa a ilustração de um esquema de impermeabilização. 
Figura 2 - Configuração de uma camada de proteção de fundo.

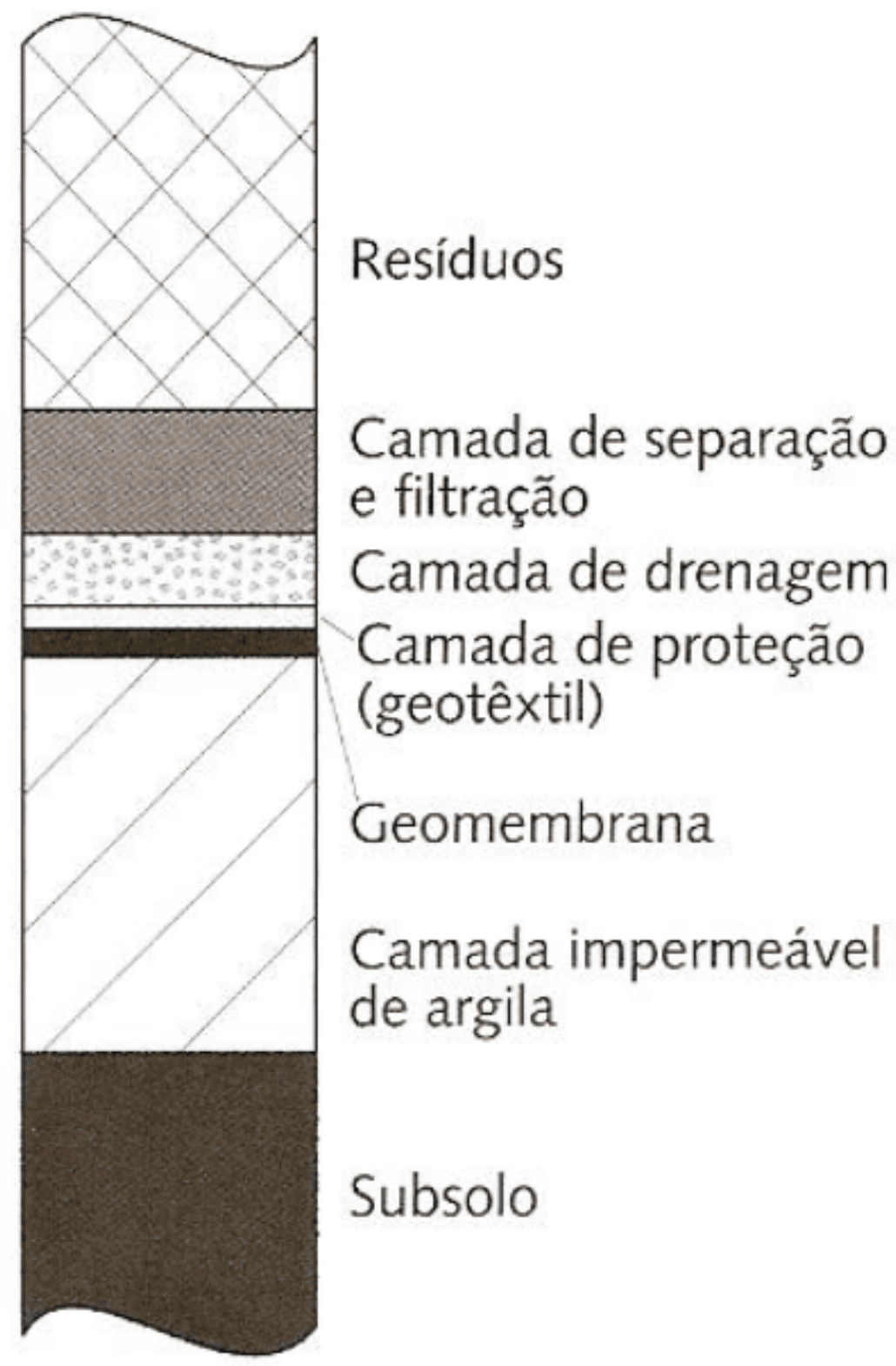

Fonte: Boscov, 2008.

A Figura 2 utiliza os métodos de uma camada compactada de argila e outra camada utilizando a geomembrana.

RC: 88511

Disponível em: https://www.nucleodoconhecimento.com.br/engenharia-civil/cidade-de-guajeru 


\subsubsection{SISTEMA DE DRENAGEM DO LIXIVIADO “CHORUME”}

Para o sistema de drenagem do lixiviado é de suma importância que o sistema auxilie na diminuição da pressão do líquido na massa dos resíduos sólidos, a fim de garantir uma excelente estabilidade do maciço, acarretando também na redução dos riscos de infiltrações no subsolo (BUSCOV, 2008). Conforme Resolução do CONAMA, ํㅜ 308, de 21 de março de 2002, o sistema de drenagem deve conduzir o lixiviado para local específico, onde posteriormente passa por um processo de tratamento, tendo como finalidade a preservação do meio ambiente, protegendo o lençol freático das emanações dos líquidos provenientes da massa dos resíduos sólidos, o chorume, e também dos gases, ambos oriundos da decomposição.

Segundo Bidone (2001), o chorume é um líquido proveniente da decomposição anaeróbica, esse processo juntamente com a ação da chuva no aterro sanitário possibilita lixiviar os compostos orgânicos que se encontram no aterro. As características do lixiviado são: cor escura, odor nauseante, e um elevado potencial de poluição se comparado com efluentes domésticos.

Na Figura 3, pode-se observar um sistema de material filtrante executado diretamente no solo de fundação.

RC: 88511 
Figura 3 - Sistema de drenagem de lixiviado no aterro de Rio Formoso em Pernambuco-RE.

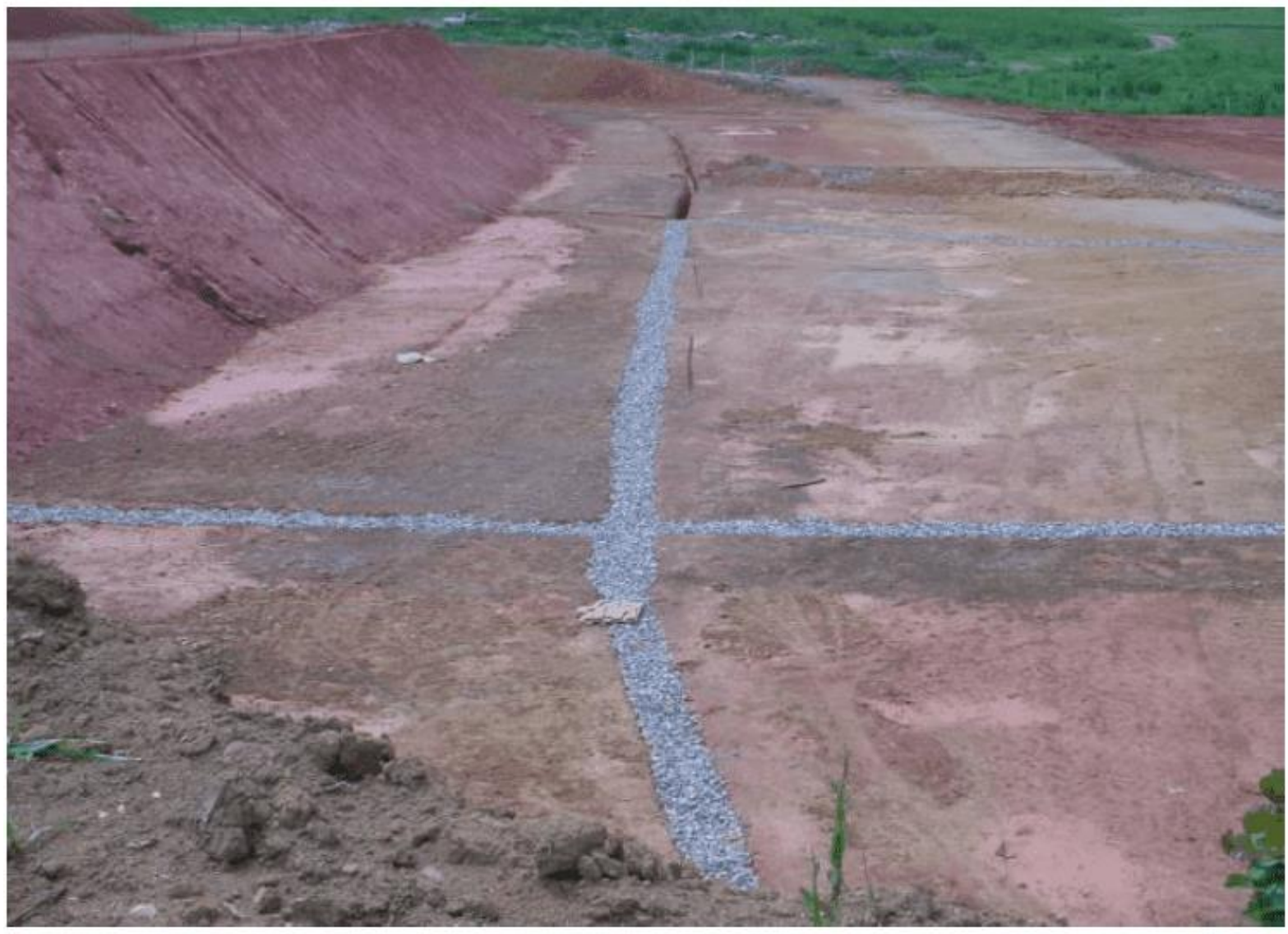

Fonte: Alves, 2015.

O sistema de drenagem apresentado na Figura 3, demonstra características do tipo espinha de peixe, em valas de material britado de graduação graúdo, o que possibilita melhor percolação dos fluidos, este sistema trabalha conectado aos drenos do biogás.

\subsubsection{SISTEMA DE DRENAGEM DE GASES}

Para um sistema de drenagem de gases, segundo Alves (2015) o sistema tem como finalidade drenar os gases provenientes da decomposição anaeróbica dos resíduos confinados no aterro sanitário, entre eles, temos basicamente o gás carbônico (CO2) e o metano $(\mathrm{CH} 4)$, que por sua vez é altamente inflamável. Evitando também o 
aumento de pressões internas, impedindo a instabilidade do maciço proveniente dos gases no interior da massa dos resíduos.

Consequentemente, os drenos dos gases podem ser integrados juntamente com o sistema de drenagem do lixiviado. Certamente essa junção se torna benéfica, pois, o líquido percolado gerado por ação dos resíduos sólidos podem ser canalizados pelo sistema de gases.

As Figuras 4 e 5 mostram um exemplo de drenos de gases que são formados por tubos de concreto, onde, são perfurados e necessariamente revestidos com britas.

Figura 4 - Esquematização do dreno de gás e sistema passivo (Queima em PDR).

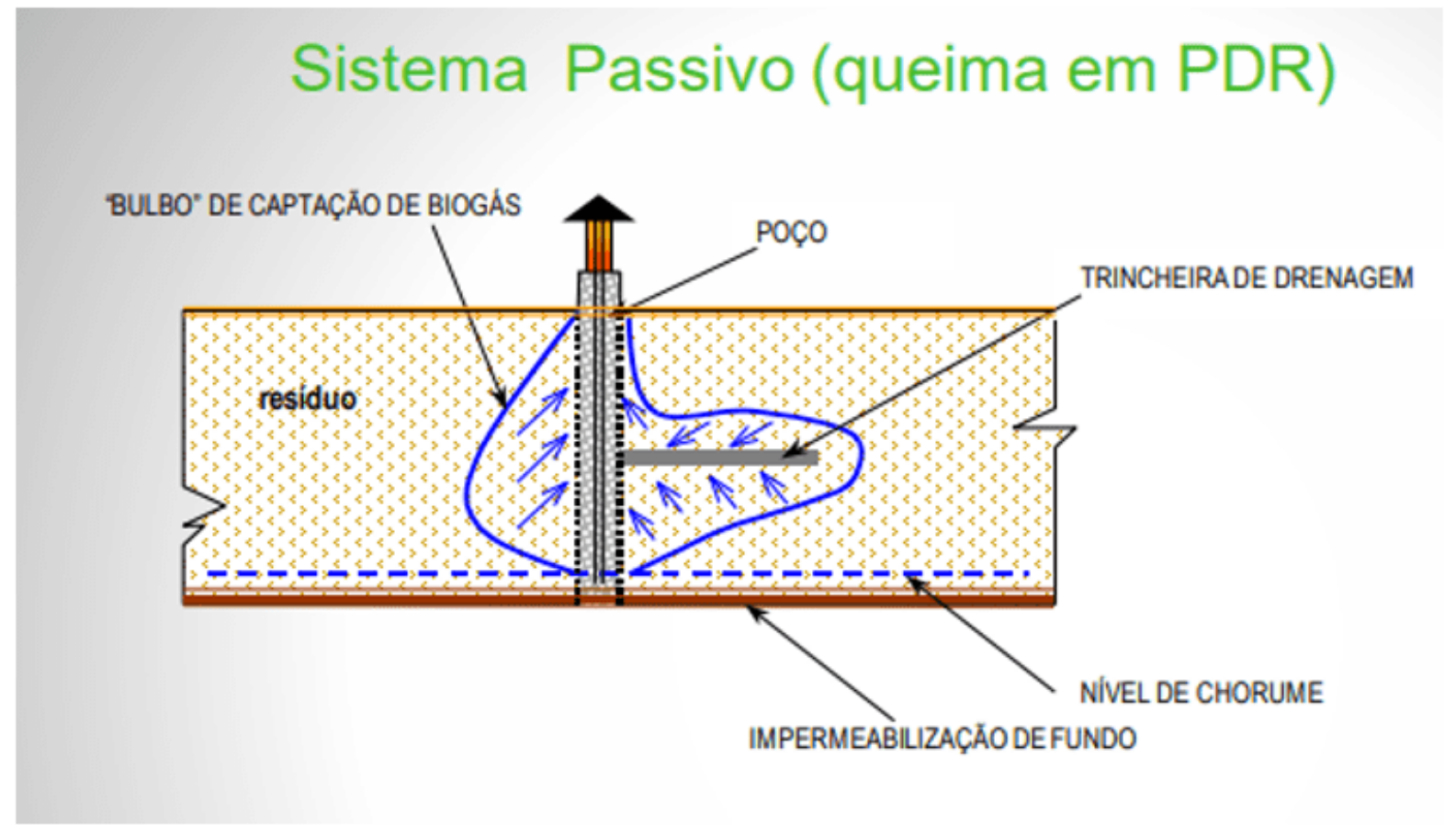

Fonte: Delbin, 2016.

RC: 88511

Disponível em: https://www.nucleodoconhecimento.com.br/engenharia-civil/cidade-de-guajeru 
Figura 5 - Foto do dreno de gás e sistema passivo (Queima em PDR).

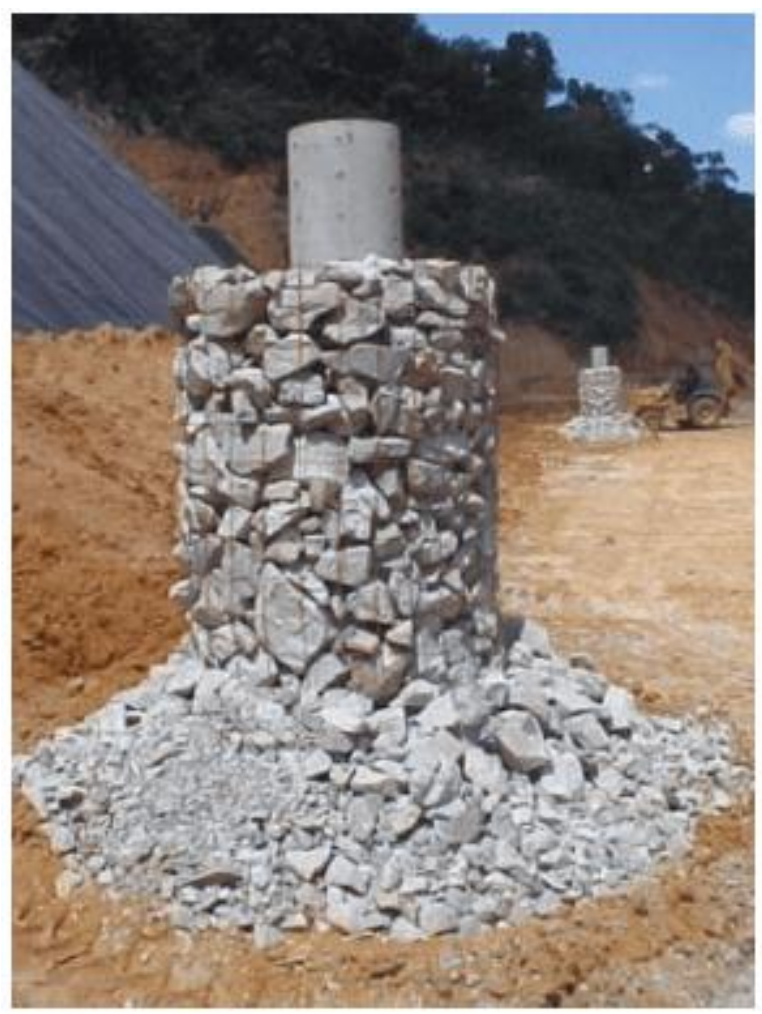

Fonte: Alves, 2015.

Por ser altamente poluente, o gás metano $(\mathrm{CH} 4)$, um dos principais responsáveis pelo efeito estufa, que agrava de maneira exorbitante o aquecimento global (ECYCLE, 2014), passa pelo processo de queima passiva deste gás, transformando-o em gás carbônico, que por sua vez é menos prejudicial ao meio ambiente, conforme mostrado o sistema de drenagem de gases na Figura 5.

\subsubsection{CAMADA DE COBERTURA E SISTEMA DE DRENAGEM DE ÁGUAS PLUVIAIS}

As camadas de cobertura do maciço de um aterro sanitário podem ser classificadas em três tipos: camada diária, camada intermediaria e a camada final. Estas camadas têm como finalidade proteger a superfície da célula, permitir o acesso das máquinas,

$\mathrm{RC}: 88511$

Disponível em: https://www.nucleodoconhecimento.com.br/engenharia-civil/cidade-de-guajeru 
evitar exalação de odores, presença de animais e não permitindo o contato de pessoas(catadores) com os resíduos.

Deste modo, segundo (CEMPRE, 2010), as camadas diárias são realizadas no final de cada jornada de trabalho utilizando cerca de $20 \mathrm{~cm}$ de solo. A camada intermediaria se adequa quando o aterro passa por um período acima de 1 ano inativo devido à conclusão da célula, onde exige uma camada de aproximadamente $30 \mathrm{~cm}$ de solo argiloso compactado.

A camada final por sua vez tem como finalidade reduzir a saída de gases produzida pela decomposição e impermeabilizar a superfície para reduzir a infiltração de água da chuva, reduzindo a produção de lixiviado. Para esta camada, é utilizado um solo argiloso compactado e com $60 \mathrm{~cm}$ de espessura (SECRETARIA NACIONAL DE SANEAMENTO AMBIENTAL, 2008).

O aterro deve possuir de um sistema de drenagem de águas pluviais eficiente, para prevenir erosão e rompimento dos taludes, protegendo assim o corpo do aterro sanitário.

A Figura 6 mostra os aspectos gerais apresentados, evidenciando detalhadamente cada etapa do aterro sanitário, ressaltando a importância de todos os sistemas.

RC: 88511 
Figura 6 - Aspectos gerais do aterro sanitário.

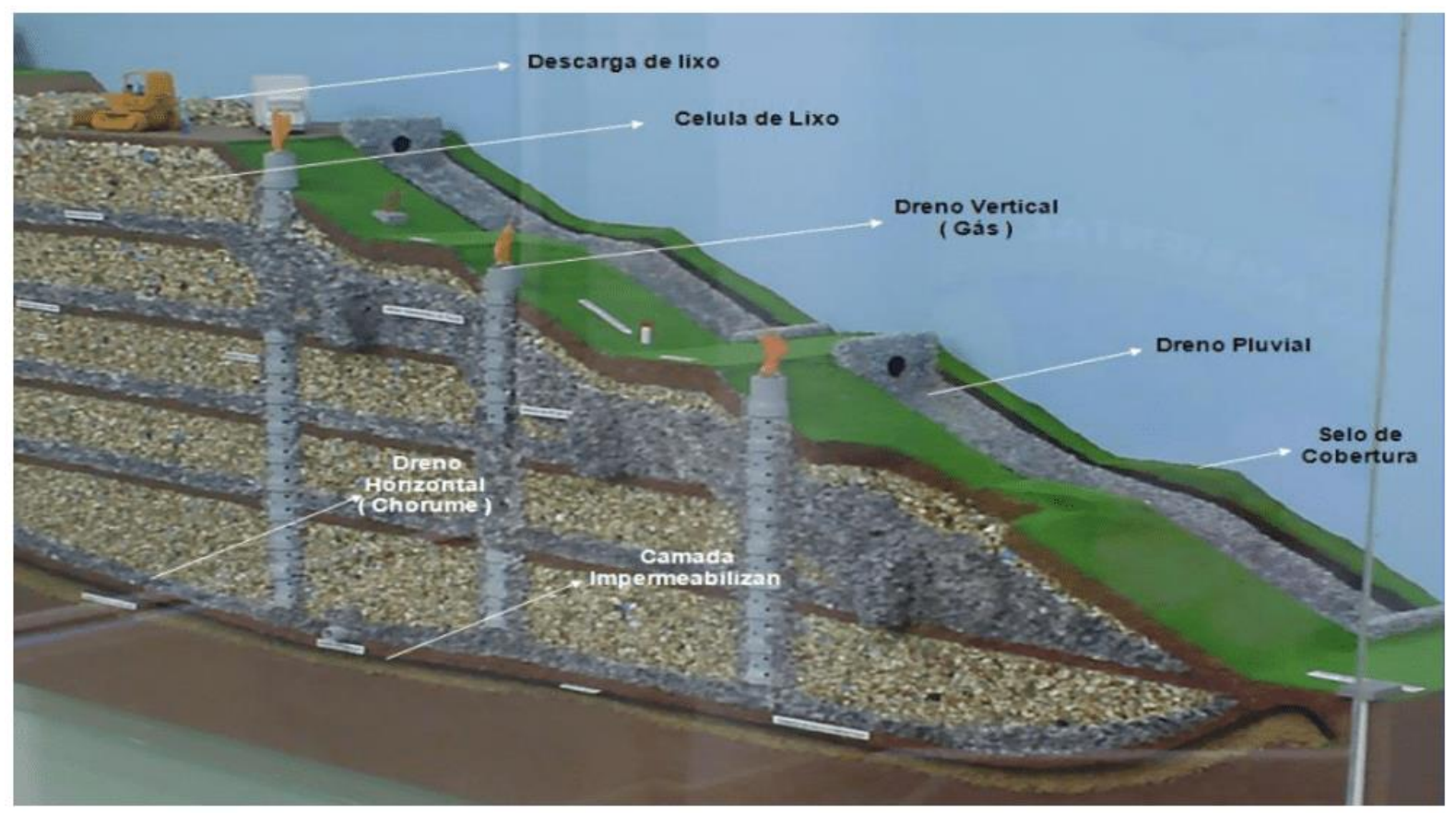

Fonte: Delbin, 2016.

A Figura 6 apresenta um processo continuado de uso de um aterro sanitário, demonstrando os níveis inferiores da célula já compactados e com suas respectivas camadas de solo intermediários e de cobertura final.

\section{PROCEDIMENTOS METODOLÓGICOS}

Este estudo foi realizado com base em pesquisas sobre a cidade de Guajeru - BA, município situado na região sudoeste do estado da Bahia, que de acordo com o IBGE (2010), possui uma área de unidade territorial de $872,867 \mathrm{Km}^{2}$, inserida no sudoeste da Bahia, distando aproximadamente $657 \mathrm{Km}$ da Capital do estado, suas coordenadas geográficas são $14^{\circ} 32^{\prime} 49^{\prime \prime} \mathrm{S}$ e $41^{\circ} 56^{\prime} 24^{\prime \prime} \mathrm{O}$ e sua altitude é de $628 \mathrm{~m}$ acima do nível do mar (GOOGLE EARTH, 2021). 
A partir de pesquisas bibliográficas e em sites oficiais da República Federativa do Brasil e do Estado da Bahia, foi possível estabelecer o perfil do município e seu status atual quanto a destinação ambientalmente adequada para o resíduo sólido urbano.

O local determinado para a implantação do futuro aterro sanitário, seria o mesmo que atualmente é utilizado para o descarte dos resíduos do município, ainda na condição de aterro controlado considerando suas características. Na Figura 7 pode-se observar o local destinado ao aterro sanitário, que abrange uma área total de 1,1026 ha, localiza-se sob as coordenadas geográficas $14^{\circ} 32441.80^{\prime \prime} \mathrm{S}$ e $41^{\circ} 57^{\prime} 51.54$ "O. O acesso, se dá pela Rua Genésio de Souza Brito, a uma distância de 2,73 Km da cidade como mostra o traçado em vermelho na Figura 7 (GOOGLE EARTH, 2020).

Figura 7 - Visão de satélite da vista superior do aterro controlado de Guajeru- BA.

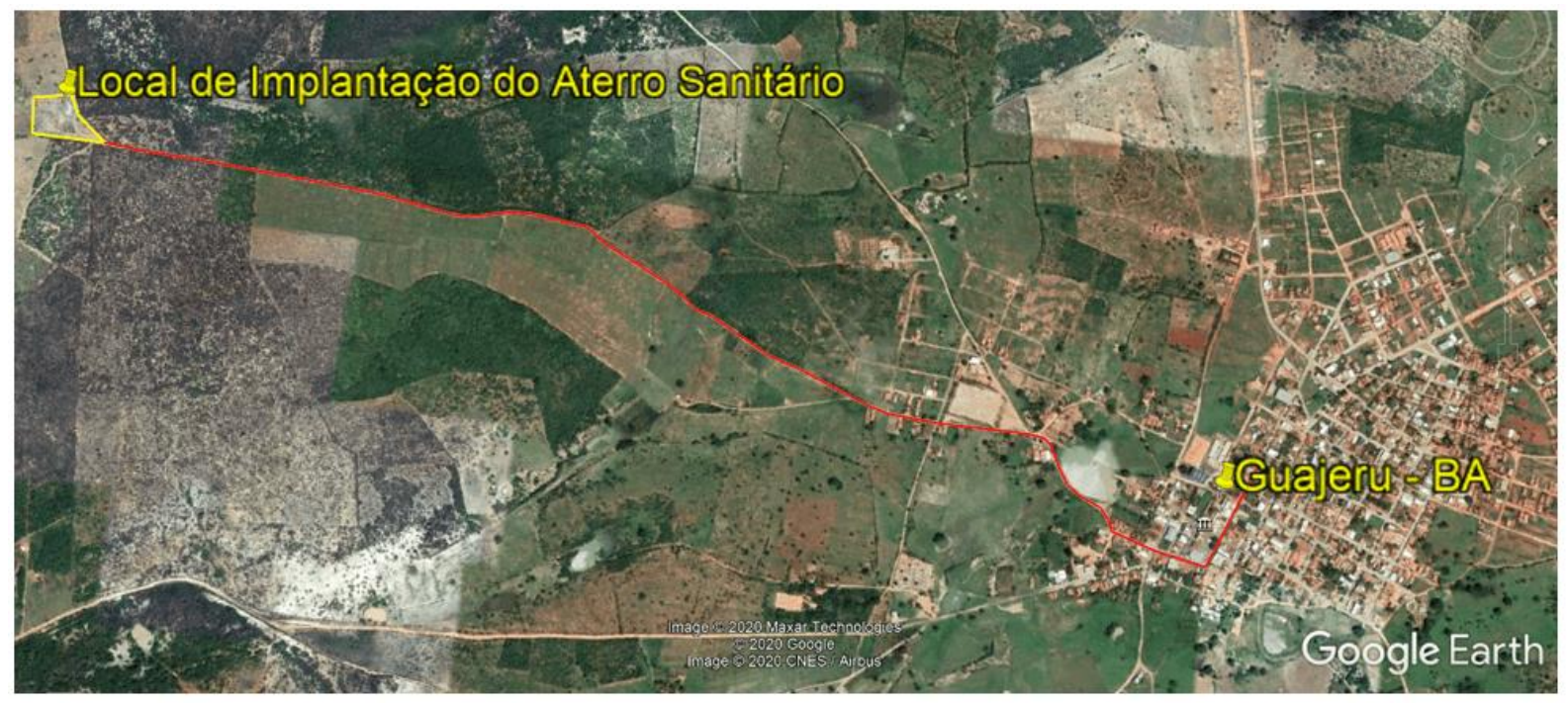

Fonte: Google Earth, 2020.

\subsection{ESTUDOS PRELIMINARES}

Para a elaboração do projeto e dimensionamento da célula do aterro sanitário, foi necessário realizar o levantamento do potencial gerador de resíduos do município e das características geológicas do solo, que foram determinantes no desenvolvimento deste trabalho.

$\mathrm{RC}: 88511$

Disponível em: https://www.nucleodoconhecimento.com.br/engenharia-civil/cidade-de-guajeru 


\subsubsection{POTENCIAL GERADOR DE RESÍDUOS DO MUNICÍPIO}

Segundo o (IBGE, 2010), o município de Guajeru - BA de acordo com o último censo registrado possui uma população de 10.412 habitantes, com densidade demográfica de 12,12 hab/km2. Para tanto, com base nas informações do diagnóstico sobre Resíduos Sólidos (RS) de 2019, realizado pelo Sistema Nacional de Informações sobre Saneamento (SNIS), que através da coleta de dados fornecidos pelos municípios que participaram, traça um perfil dos municípios brasileiros, classificandoos de acordo com a faixa populacional, deste modo estabelecendo parâmetros para análise. Conforme o diagnóstico RS 2019 mencionado, a quantidade per capita de resíduos sólidos gerados para cidades de até 30 mil habitantes, constantes na faixa populacional 1, na qual o município de Guajeru está inserido, é de 0,85 kg/hab/dia, conforme exibido na Tabela 1.

Tabela 1 - Faixa Populacional x Massa coletada Per capita

\begin{tabular}{|c|c|c|}
\hline $\begin{array}{l}\text { Faixa } \\
\text { Populacional }\end{array}$ & Intervalo da faixa (hab.) & $\begin{array}{l}\text { Massa coletada Per capita } \\
\text { (kg/hab/dia) }\end{array}$ \\
\hline 1 & População total $\leq 30$ mil & 0,85 \\
\hline 2 & $\begin{array}{l}30 \text { mil < População total } \leq \\
100 \text { mil }\end{array}$ & 0,89 \\
\hline 3 & $\begin{array}{l}100 \text { mil < População total } \leq \\
250 \text { mil }\end{array}$ & 0,89 \\
\hline 4 & $\begin{array}{l}250 \text { mil < População total } \leq 1 \\
\text { milhão }\end{array}$ & 0,96 \\
\hline 5 & $\begin{array}{l}1 \text { milhão < População total } \leq \\
4 \text { milhões }\end{array}$ & 1,10 \\
\hline 6 & População total > 4 milhões & 1,03 \\
\hline
\end{tabular}

Fonte: Diagnostico Resíduos Sólidos 2019 - SNIS.

RC: 88511

Disponível em: https://www.nucleodoconhecimento.com.br/engenharia-civil/cidade-de-guajeru 


\subsubsection{DETERMINAÇÃO DO TIPO DE SOLO}

O tipo de solo foi definido a partir da escolha do local, que para este projeto será no mesmo local do aterro controlado existente, observado na Figura 7. Devido a impossibilidade na realização de uma da sondagem de simples reconhecimento, o Standard Penetration Test (SPT), que segundo ABNT NBR 6484:2001 tem como finalidade a determinação dos tipos de solos, suas profundidades e a posição do nível d'água, apresentando também os índices de resistência a penetração a cada metro, o estudo do solo foi baseado nos dados obtidos no Mapa Geológico do Estado da Bahia (SOUZA et. al., 2003), conforme mostrado na Figura 8.

$\mathrm{RC}: 88511$ 
Figura 8 - Mapa geológico do estado da Bahia

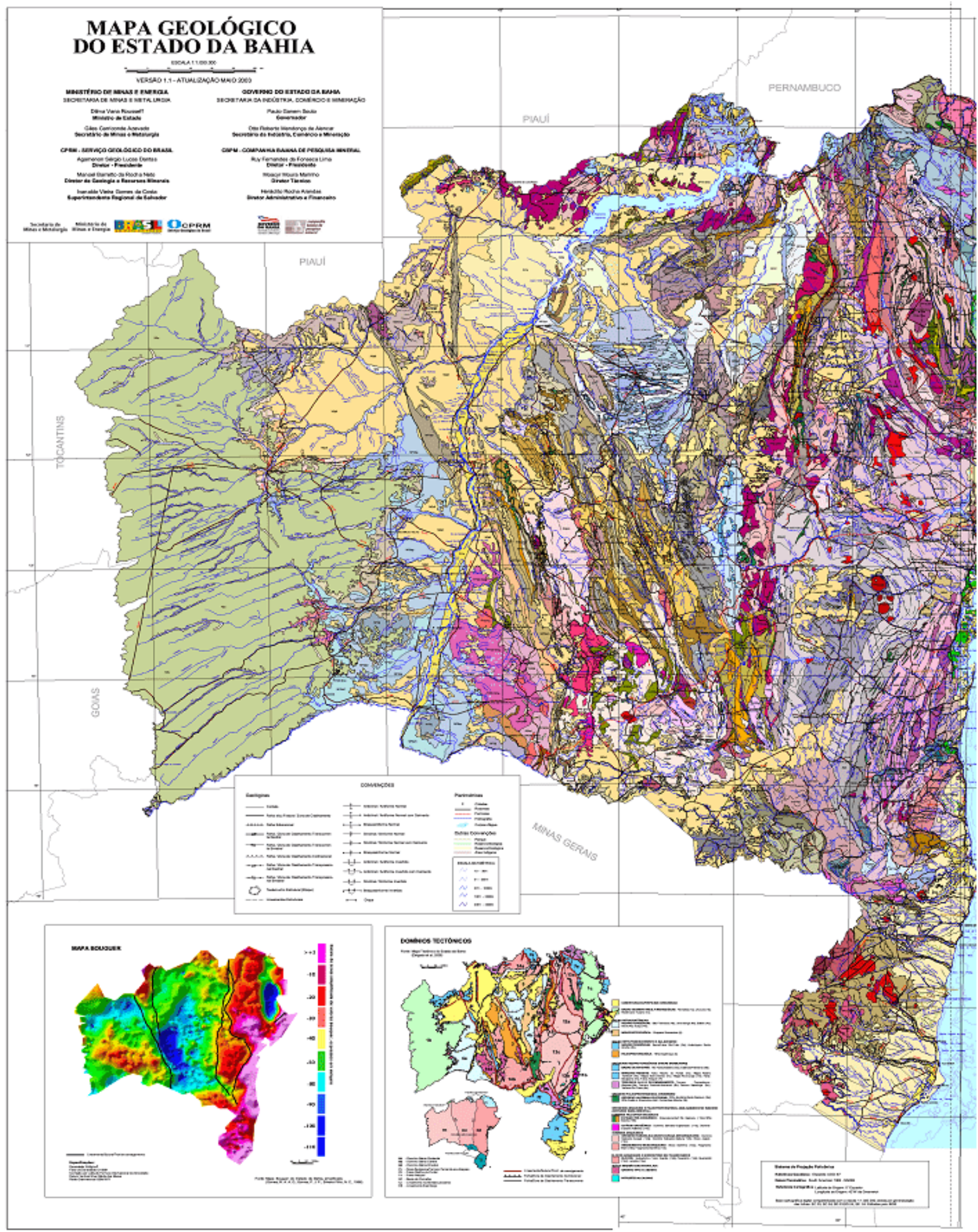

Fonte: (SOUZA et. al., 2003)

$\mathrm{RC}: 88511$

Disponível em: https://www.nucleodoconhecimento.com.br/engenharia-civil/cidade-de-guajeru 
O estudo das características do solo é de extrema relevância, com ele podemos conhecer a composição do solo, sua capacidade portante enquanto fundação do aterro e a profundidade do lençol freático, que segundo a ABNT NBR 15849:2010, a distância mínima entre a célula escavada e o lençol freático deve ser de 3,0 m. O tipo de solo é decisivo na escolha do local, visto que um solo rochoso dificulta o processo de escavação e pode inviabilizar a implantação do aterro, por questões técnicas e financeira. Como mostrado na Figura 9, detalhe extraído do Mapa Geológico Do Estado Da Bahia (SOUZA et. al., 2003), pode-se determinar que de maneira genérica o solo do município de Guajeru e região é do tipo A2gm - Ortognaisse migmatítico tonalítico-trondhjemítico-granodioritico, com enclaves máfico e ultramáfico, em geral, resultantes da erosão de gnaisses e migmatitos, ambas rochas metamórficas derivadas do granito, parte da formação geológica do complexo gavião. 
Figura 9 - Ampliação da Legenda do Mapa geológico

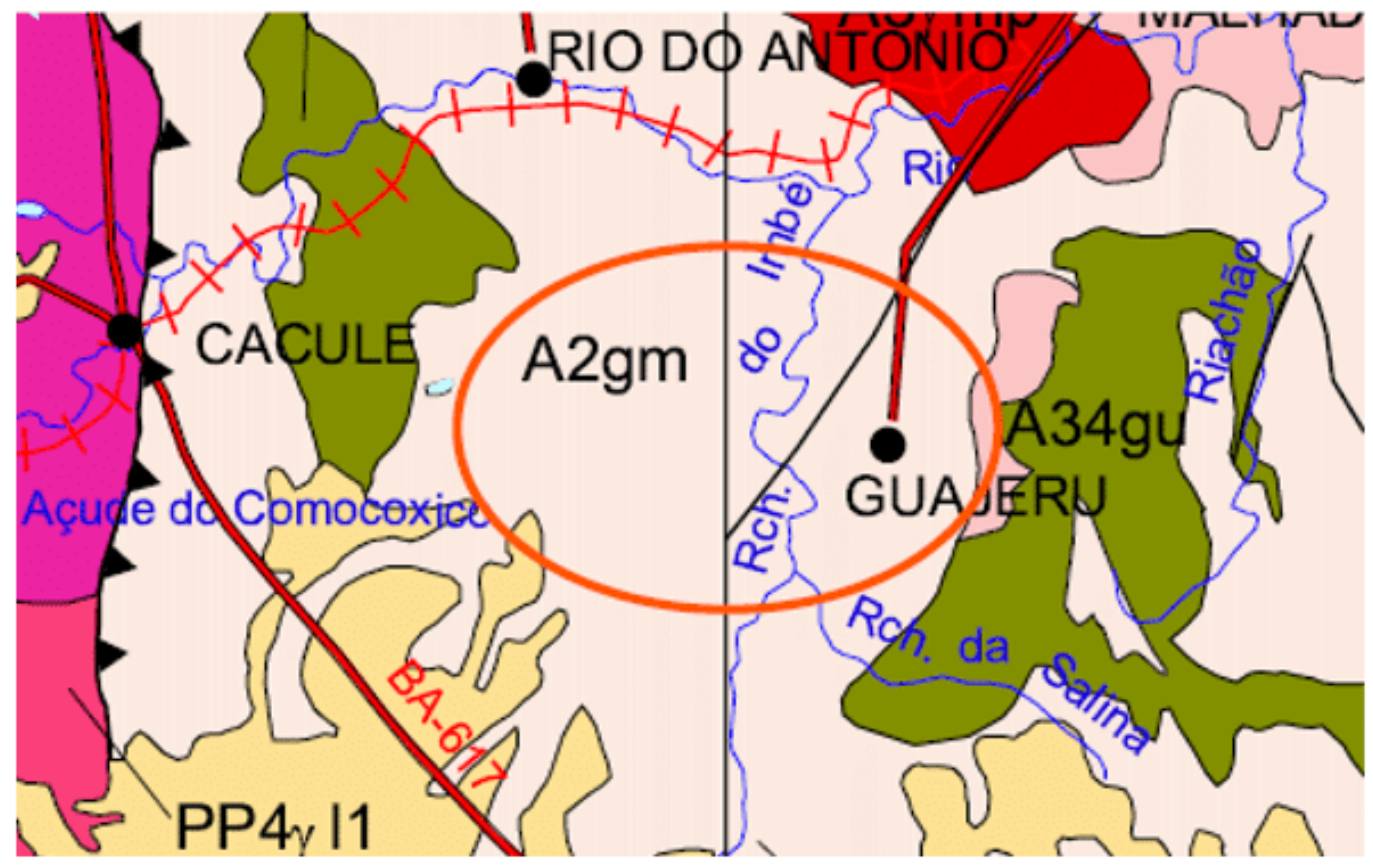

PALEOARQUEANO (3600 - $3200 \mathrm{Ma})$

A2y $\mathrm{mm}$ Granitóide Mariana: ortognaisse monzogranítico a tonalítico, calcialcalino de alto $\mathrm{K}$ metaluminoso ( $3259 \mathrm{Ma} \mathrm{Pb}-\mathrm{Pb}$ )

Greenstone Belt de Mundo Novo

A2 $\mathrm{mn}$ Metaultramafito, metabasalto, metadacito, metarriodacito, metatufo, rocha calcissilicá-

A2mr

tica, anfibolito, gnaisse aluminoso, metachert, formaçăo ferrifera, xisto e quartzito ( $3305 \mathrm{Ma} \mathrm{U}-\mathrm{Pb}$ )

\section{Complexo Gaviāo}

A2gm Ortognaisse migmatítico tonalítico-trondhjemítico-granodiorítico, com enclaves máfico e ultramáfico ( $3300 \mathrm{Ma} \mathrm{Pb}-\mathrm{Pb} 2912 \mathrm{Ma} \mathrm{Pb}-\mathrm{Pb}$ )

\section{Complexo Mairi} A2mo Ortognaisse migmatítico, tonalítico-trondhjemítico-granodiorítico, com enclaves máfico

A2ttg

Domos de Sete Voltas, Boa Vista/Mata Verde e Corpos de Bernarda e Aracatu: Ortognaisse tonalítico-trondhjemitico-granodiorítico ( $3403 \mathrm{Ma} \mathrm{U}-\mathrm{Pb} 3240 \mathrm{Ma} \mathrm{Pb}-\mathrm{Pb}$ )

Fonte: (SOUZA et. al., 2003)

Um dos critérios que é preciso atender com a finalidade de minimizar os impactos ambientais, é estabelecer a área de atividades do aterro com uma distância mínima de $1500 \mathrm{~m}$ do núcleo populacional, a partir do perímetro da área. A zona de operação deve estar fora da área onde tem influência direta com mananciais de abastecimento,

$\mathrm{RC}: 88511$

Disponível em: https://www.nucleodoconhecimento.com.br/engenharia-civil/cidade-de-guajeru 
estar distante $300 \mathrm{~m}$ do perímetro da área de residências e a uma distância de $200 \mathrm{~m}$ de mananciais e rios. Conforme mostrado na Figura 10, o local escolhido para este projeto, atende às recomendações citadas anteriormente, conforme preconiza a ABNT NBR 15849:2010.

Figura 10 - Visão superior do local de implantação da célula

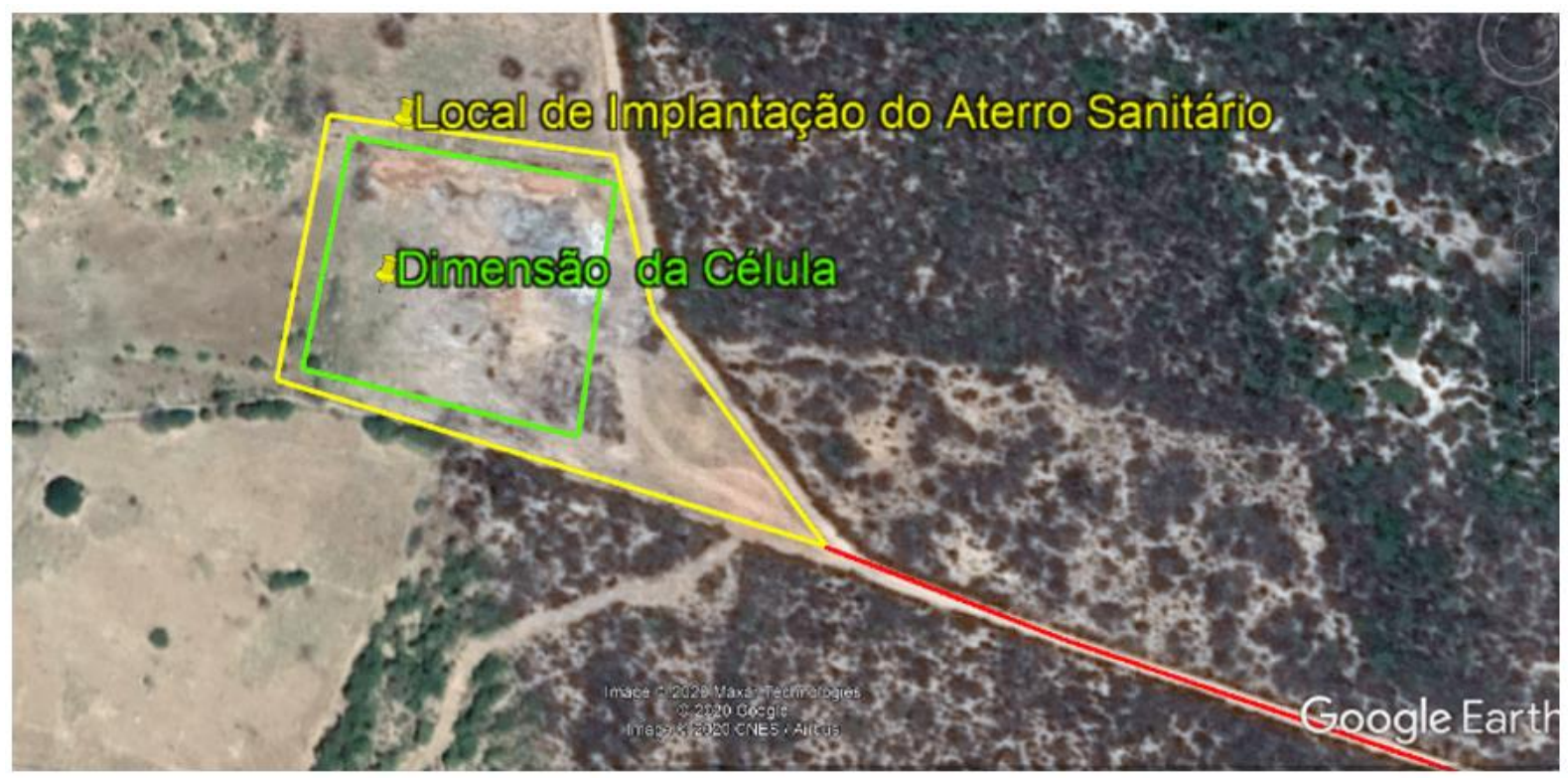

Fonte: Google Earth, 2021.

Na figura 10, pode-se observar o local destinado ao aterro e onde será implantado a célula seguindo todos os critérios citados acima e informando as respectivas dimensões da célula de $100 \mathrm{~m} \times 100 \mathrm{~m}$ totalizando uma área de $10.000 \mathrm{~m}^{2}$.

\subsection{CÁLCULOS PARA O PROJETO}

Os cálculos para o dimensionamento da célula para o projeto do aterro sanitário de Guajeru, foram realizados com base nos parâmetros coletados nas pesquisas. Foi definido como vida útil de projeto, o período de 15 anos, sendo este o tempo de atividade mínimo para um aterro sanitário de pequeno porte, além do período de monitoramento de dez anos caso exista sistema de drenagem de gases e do lixiviado (ABNT NBR 15849:2010).

RC: 88511

Disponível em: https://www.nucleodoconhecimento.com.br/engenharia-civil/cidade-de-guajeru 
De acordo com JRAMILLO (1991), inicialmente, obtêm-se a massa total estimada da produção de resíduos gerado em toda a vida útil da célula, conforme a equação (1).

$$
M=(P o p * \text { Resíduos } * 365 * V u) / 1000
$$

Onde, é a massa total do resíduo gerado em toneladas; é a quantidade de habitantes na cidade de Guajeru; é a quantidade de resíduo per capita gerado no município; é a vida útil do aterro em anos.

Após determinar da massa total $(M)$ de resíduos produzidos no período de atividade do aterro, calcula-se o volume total ( $V$ ) estimado, majorado em $20 \%$ para incluir o material utilizado na camada de cobertura, como pode ser observado na equação (2):

$$
V=(M / \gamma) * 1,2
$$

Onde, é volume total do resíduo gerado $\mathrm{em}^{3}$; é a massa total do resíduo gerado em toneladas; é massa específica expressa em ton $/ \mathrm{m}^{3}$. Adota-se o valor de $0,7 \mathrm{ton} / \mathrm{m}^{3}$ para massa específica; Deve-se acrescer $20 \%$ corresponde ao volume de terra para cobrimento dos resíduos em $\mathrm{m}^{3}$ (CEMPRE, 2018).

Munido destas informações, verifica-se a capacidade estimada para cada tronco da célula, considerando a área preestabelecida em projeto para a implantação, ou seja, o volume de resíduos suportado por cada camada. Para tanto, este valor é obtido através da equação (3).

$$
V t=h / 3 *\left(S_{B}+\sqrt{S_{B} * S_{b}}+S_{b}\right)
$$

Onde é o volume do tronco da célula $\mathrm{em}^{3}$, é a altura de empilhamento do resíduo por camada; $S_{B}$ é a área da maior face da camada em metros quadrados; ${ }{ }_{b}$ é a RC: 88511 
área da menor face da camada em metros quadrados. O offset, resultante da inclinação do talude é o responsável pela diferença entre a área da face inferior e a área da face superior da camada, como apresentado na equação acima.

\section{ANÁLISE DOS RESULTADOS}

Os dados coletados sobre a cidade de Guajeru, permitiram o desenvolvimento dos cálculos para o dimensionamento da célula. No primeiro momento, foi possível determinar a massa e o volume total de resíduo produzidos pelo município no período de 15 anos, vida útil adotada para o projeto, conforme os dados apresentados na Tabela 2:

Tabela 2 - Geração de Resíduos.

Dados da Equação 01

\begin{tabular}{|l|l|}
\hline População & $10.412 \mathrm{mil}$ \\
\hline Resíduos (per capta) & $0,85 \mathrm{~kg} / \mathrm{hab} / \mathrm{dia}$ \\
\hline Vida Útil de Projeto & $15 \mathrm{anos}$ \\
\hline Dados da Equação 02 & \\
\hline Massa total de resíduos gerado & $48,455 \mathrm{ton}$ \\
\hline Massa específica do resíduo & $0,7 \mathrm{ton} / \mathrm{m}^{3}$ \\
\hline Volume previsto em 15 anos & $83.065 \mathrm{~m}^{3}$ \\
\hline
\end{tabular}

Fonte: Autoria própria.

Utilizando a área destinada para a implantação da célula do aterro sanitário e as dimensões predefinidas - aproveitando das condições de planialtimetria do terreno para cada camada ou tronco, bem como sua altura e a inclinação do talude, estimouse a capacidade de armazenamento de cada tronco e em consequência a volume total suportado por esta célula, como pode ser verificado na Tabela 3.

$\mathrm{RC}: 88511$

Disponível em: https://www.nucleodoconhecimento.com.br/engenharia-civil/cidade-de-guajeru 
Tabela 3 - Volume dos Troncos

\begin{tabular}{|l|l|}
\hline Tronco & Volume unitário $\left(\mathrm{m}^{3}\right)$ \\
\hline Tronco 1 & $36.885,33$ \\
\hline Tronco 2 & $30.997,33$ \\
\hline Tronco 3 & $25.621,33$ \\
\hline Capacidade total da célula & 93.504 \\
\hline Vida útil estimada para célula & $\mathbf{1 6 , 8 8}$ anos \\
\hline
\end{tabular}

Fonte: Autoria própria.

A partir da análise dos resultados, pode-se prever uma sobrevida para o aterro em estudo, considerando que o volume de resíduo suportado pela célula é maior do que o volume de resíduo produzido pelo município no período de 15 anos, o que resultou num acréscimo de 1,88 anos no tempo de atividade desta unidade, estimando-se uma vida útil total para a célula de 16,88 anos, que equivale a 16 anos, 10 meses e 18 dias. Importante ressaltar que, para o valor utilizado no dimensionamento referente à população do município, foi adotado o total apurado no último senso do IBGE (2010), pois na estimativa da população para o ano de 2020, há uma expectativa de redução no número de habitantes em aproximadamente $36 \%$ daquele total, desta forma foi considerado o pior cenário para os cálculos, condição esta que dá margem para um aumento na vida útil do aterro.

A Figura 11 é uma representação técnica de seção típica da célula do aterro sanitário, com detalhamento de suas dimensões: largura e comprimento com extensão iguais a $100 \mathrm{~m}$, altura total de $12 \mathrm{~m}$, sendo que $4 \mathrm{~m}$ corresponde ao trecho escavado, ou seja, abaixo do nível do terreno, e $8 \mathrm{~m}$ acima do nível do solo. Os taludes possuem uma inclinação de 1:1, destinando uma área a vias de serviço, voltadas para circulação e acesso de veículos.

RC: 88511

Disponível em: https://www.nucleodoconhecimento.com.br/engenharia-civil/cidade-de-guajeru 
Figura 11 - Modelo do aterro sanitário em planta baixa e corte

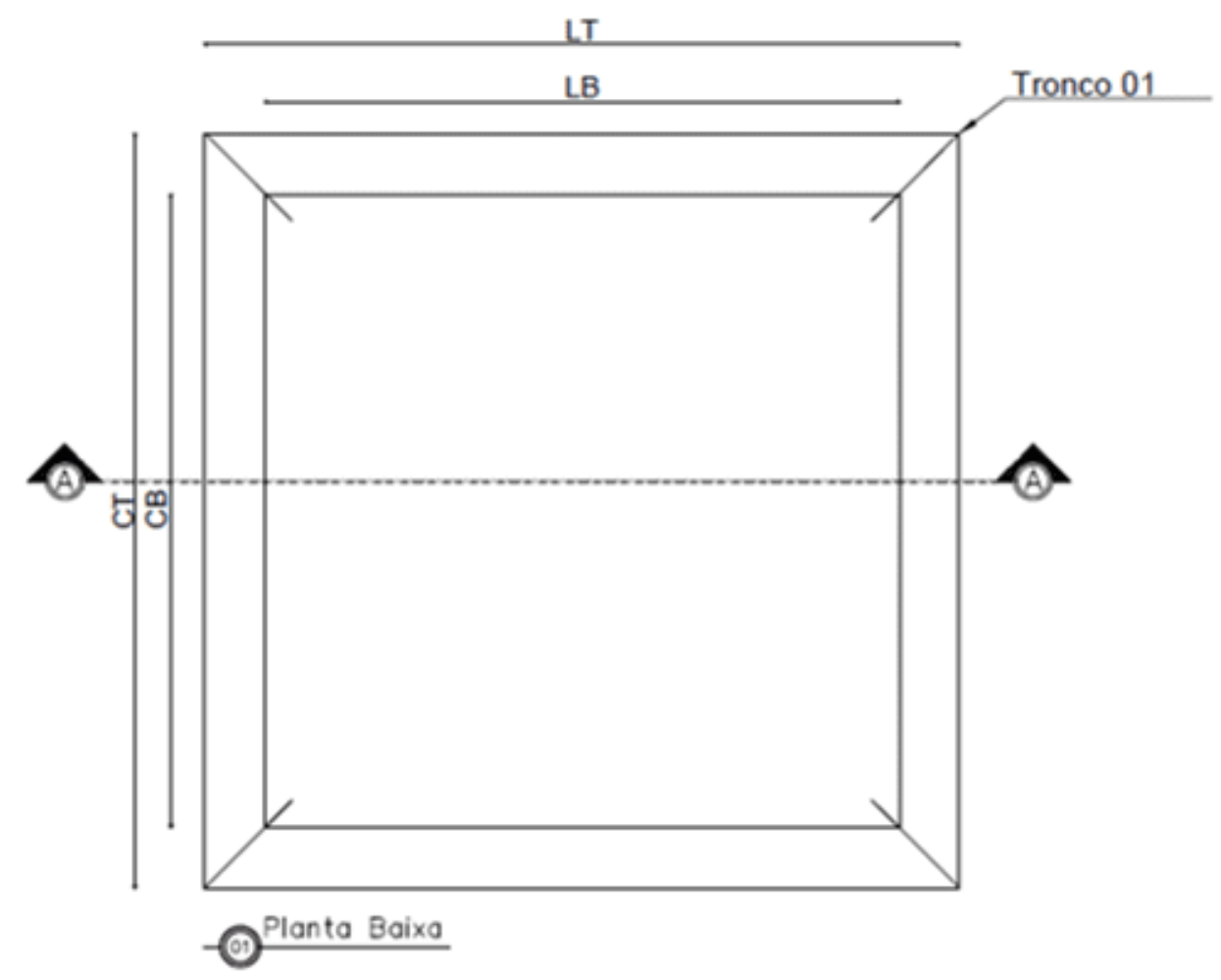

LEGENDA:

LT-Largura do topo da celula

LB-Largura da base da celula

CT-Comprimento do topo da celula

LB-Comprimento da base da celula

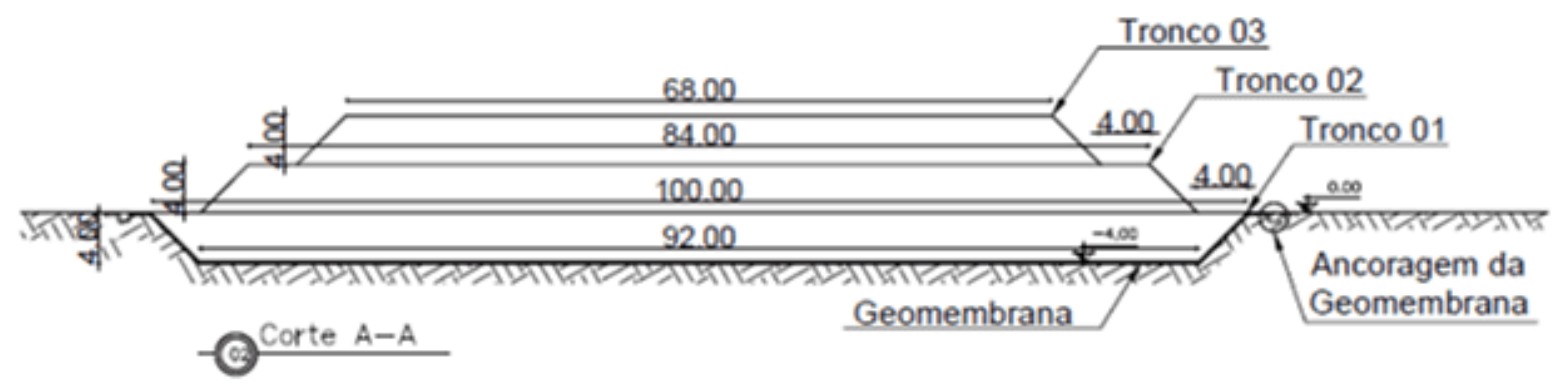

Fonte: Autoria própria, 2021.

A figura 11 apresenta as camadas projetadas para o aterro, também denominadas tronco. Observa-se ainda o perfil do terreno, destacando a presença da geomembrana como componente do sistema de impermeabilização do solo.

RC: 88511

Disponível em: https://www.nucleodoconhecimento.com.br/engenharia-civil/cidade-de-guajeru 
Importante ressaltar que, mesmo não estando no escopo deste trabalho, outras estruturas e equipamentos devem ser previstos e dimensionados para a implantação de um aterro sanitário, entre eles temos: instalações prediais para escritório e acomodações de funcionários, vias de acesso pavimentada, estacionamento e galpão de manutenção para maquinas e equipamentos, edificação de entrada, para controle de acesso de pessoas e veículos (ABNT NBR 15849:2010), sistema de drenagem do lixiviado e tratamento de gases, além do sistema de tratamento e neutralização do chorume (lagoa de tratamento).

\section{CONSIDERAÇÕES FINAIS}

Para se enquadrarem na Lei oㅜ 12.305/10, que institui a Política Nacional de resíduos sólidos (PNRS), importante mecanismo legal para o avanço das cidades e do país no enfrentamento dos problemas ambientais, sociais e econômico, no que tange ao manejo e tratamento dos resíduos sólidos, sendo posteriormente alterada e atualizada pela Lei $n=14.026 / 2020$, que estabelece $o$ ano de 2024 como prazo limite para cidades com população abaixo de 50 mil habitantes se adequarem, eliminando por completo os lixões e aterros controlados, condição na qual se encontra a cidade de Guajeru (BRASIL, Lei no 14.026, de 15 de julho de 2020).

Os municípios com proximidades geográficas, que fazem parte do Consorcio Intermunicipal de Desenvolvimento do Complexo Nascentes do Pantanal do MatoGrossense, criaram o consórcio voltado para a solução das questões do saneamento básico em suas cidades e deste modo dividem os custos de implantação e de operação do serviço de coleta e disposição final dos resíduos, tornando possível a oferta deste serviço à comunidade, além da descontaminação e preservação do meio ambiente.

A cidade de Guajeru, necessita de uma atenção especial dos poderes legislativo e executivo, assim como se faz de extrema importância uma maior cobrança dos setores organizados da sociedade, para que o debate sobre o projeto e implantação do aterro

RC: 88511

Disponível em: https://www.nucleodoconhecimento.com.br/engenharia-civil/cidade-de-guajeru 
sanitário se inicie o mais breve possível, considerando a complexidade dos processos de licitação, projeto, licenciamento ambiental e mobilização dos recursos no orçamento do município, sendo este último o maior obstáculo. Para tanto, Guajeru, por intermédio do seu Gestor, pode buscar parcerias com as cidades circunvizinhas, seguindo o exemplo dos munícipios do Mato Grosso, criando um consorcio público em sua microrregião com o intuito de contornar este obstáculo, lançando mão de projetos como este, que traz à luz do debate técnico a solução para um problema crônico que atinge todo o município e seus habitantes. Outra etapa de igual importância, é a criação de programas voltados para a coleta seletiva, com trabalho de conscientização dos habitantes e implantação de cooperativas de catadores com incentivo e participação ativa do poder público municipal.

O projeto apresentado, oferece uma valiosa contribuição para Guajeru e cidades do mesmo porte em todo Brasil, que necessitam de alternativas viáveis e possíveis para se adequarem a legislação, com um equipamento do sistema de saneamento básico capaz de atender sua população por mais de 16 anos.

Conclui-se portanto, que os problemas enfrentados na área do saneamento básico numa avaliação nacional ainda estão distantes de serem resolvidos, visto que, a Lei no 12.305/10 que trata do tema sofreu alterações prorrogando o prazo limite, devido à ausência de projetos e ações para atendê-la. Com isso, uma parcela considerável da população brasileira ainda não dispõem dos serviços mínimos de saneamento, o que resulta no agravamento da saúde pública e de danos ao meio ambiente.

\section{REFERÊNCIAS}

ABNT - ASSOCIAÇÃO BRASILEIRA DE NORMAS TÉCNICAS. NBR 6484: Execução de sondagens de simples reconhecimento dos solos. Rio de Janeiro: ABNT, 2001.

ABNT - ASSOCIAÇÃO BRASILEIRA DE NORMAS TÉCNICAS. NBR 8419: Apresentação de projetos de aterros sanitários de resíduos sólidos urbanos. Rio de Janeiro: ABNT, 1992.

RC: 88511

Disponível em: https://www.nucleodoconhecimento.com.br/engenharia-civil/cidade-de-guajeru 
ABNT - ASSOCIAÇÃO BRASILEIRA DE NORMAS TÉCNICAS. NBR 8849: Apresentação de aterros controlados de resíduos sólidos urbanos. Rio de Janeiro: ABNT, 1985.

ABNT - ASSOCIAÇÃO BRASILEIRA DE NORMAS TÉCNICAS. NBR 15849: Resíduos sólidos urbanos - Aterros sanitários de pequeno porte - Diretrizes para localização, projeto, implantação, operação e encerramento. Rio de Janeiro: ABNT, 2010.

ALVES, M. C. M., 2015, Notas de Aula - Geotecnia Ambiental, UFRJ, Rio de Janeiro, RJ, Brasil.

BIDONE, Francisco Antônio. Resíduos sólidos provenientes de coletas especiais: eliminação e valorização. Brasília: FINEP/PROSAB, 2001.

BOSCOV, M. E. G. Geotecnia Ambiental. $1^{\underline{a}}$ edição, São Paulo, Editora Oficina de Textos, 2008.

BRASIL, Lei oㅜ 14.026, de 15 de julho de 2020, Diário Oficial da União: seção 1, Brasília/DF, 2020.

BRASIL, Ministério do Meio Ambiente. CONAMA. Resolução n. 308, de 21 de março de 2002. Licenciamento Ambiental de sistemas de disposição final dos resíduos sólidos urbanos gerados em municípios de pequeno porte. Disponível em: http://www.mma.gov.br/port/conama/res/res02/res30802.html >. Acesso em: 21 fev. 2021.

BRASIL, Ministério do Meio Ambiente- MMA, Lixo. Brasília/DF, 2009.

BRASIL, Ministério do Meio Ambiente, Política nacional de resíduos sólidos. Brasília/DF, 2010. 
CEMPRE. Lixo municipal: Manual de gerenciamento integrado. $3^{\text {a }}$ edição, São Paulo, 2008.

CENSO, I. B. G. E. Disponível em:< http://www. censo2010. ibge. gov. br/>. Acesso em 03 de abril de 2021, v. 23, 2010.

CNM. CONFEDERAÇÃO NACIONAL DE MUNICÍPIOS. Municípios integrantes de consórcio público inauguram aterro sanitário. Brasília: CNM, 05 de set.2019. Disponível em < https://www.cnm.org.br/index.php/comunicacao/noticias/municipiosintegrantes-de-consorcio-publico-inauguram-aterro-

sanitario\#: : :text=Os\%20Munic\%C3\%ADpios\%20consorciados\%2C\%20que\%20fizer am,que\%20atender\%C3\%A1\%20a\%2013\%20Munic\%C3\%ADpios.\&text=Pensando \%20na\%20sustentabilidade\%20e\%20no,est\%C3\%A30\%20implantando\%20a\%20col eta\%20seletiva>Acesso em: 05 de abril de 2021.

ECYCLE. O Que é Gás Metano. Disponível em: < https://www.ecycle.com.br/2426metano.html > Acesso em: 4 de abril de 2021.

FERREIRA, MAVA. Injustiça ambiental associada à disposição final de resíduos sólidos urbanos em Macaé/RJ - Do vazadouro em Águas Maravilhosas ao aterro sanitário na BR-101, 2011. Tese de Doutorado. Dissertação (Mestrado em Engenharia Ambiental) - Instituto Federal da Educação, Ciência e Tecnologia Fluminense, Macaé.

GONÇALVES, Raquel de Souza. Catadores de materiais recicláveis: trajetórias de vida, trabalho e saúde, 2004. Tese de Doutorado. Universidade Federal do Rio de Janeiro, Rio de Janeiro.

GOOGLE EARTH-MAPAS. Disponível em <https://mapas.google.com> Acesso em: 10 de Abril de 2021.

JARAMILLO, Jorge. Resíduos sólidos municipales: guia para eldiseño, construccion y operacion de rellenos sanitários manuales. In: Residuos sólidos

$\mathrm{RC}: 88511$

Disponível em: https://www.nucleodoconhecimento.com.br/engenharia-civil/cidade-de-guajeru 
municipales: guia para el diseno, construccion y operacion de rellenos sanitários manuales. 1991. p. 214-214.

MAZZER, C.; CAVALCANTI, O. A. Introdução à gestão ambiental de resíduos, 2004. Tese de Doutorado. Universidade Federal do Paraná, Maringá.

SECRETARIA NACIONAL DE SANEAMENTO AMBIENTAL (ORG.). Esgotamento sanitário: operação e manutenção de sistemas simplificados de tratamento de esgotos: guia do profissional em treinamento: nível 2 - Belo Horizonte: ReCESA, 2008.

SISTEMA NACIONAL DE INFORMAÇÕES SOBRE SANEAMENTO. Diagnóstico do manejo de resíduos sólidos urbanos: 2019. Brasília/DF: SNIS, 2019.

SOUZA, João Dalton de; MELO, Roberto Campelo de; KOSIN, Marília. Mapa geológico do estado da Bahia. Versão 1.1. Salvador: CPRM, 2003. Escala 1:1.000.000. Disponível em: http://rigeo.cprm.gov.br/jspui/handle/doc/8665. Acesso em: 06 de abril de 2021.

Enviado: Abril, 2021.

Aprovado: Junho, 2021.

RC: 88511 